\title{
PRODUCTION OF LACTIC ACID FROM SWEET MEAT INDUSTRY WASTE BY LACTOBACILLUS DELBRUKI
}

\author{
Antara Guha ${ }^{1}$, Soumitra Banerjee ${ }^{2} \&$ Debabrata Bera ${ }^{3}$ \\ ${ }^{1,2,3}$ Food Technology, Techno India, Salt lake, Kolkata, India \\ beradebabrata@yahoo.co.in
}

\begin{abstract}
A large amount of whey is discharged from sweet meat industry, which is responsible for environmental pollution and a large amount of whey protein and milk sugar are also wasted. This whey may be utilized for valuable lactic acid production. Lactobacillus delbruki was used for lactic acid production from cow-milk whey. Lactic acid production was $12.22 \mathrm{gm} / \mathrm{L}$ at pH: 6.8 , temperature: $42^{\circ} \mathrm{C}$, Inculum volume: $4 \%$, fermentation time: $24 \mathrm{hr}$, medium volume: $125 \mathrm{~mL}$ in $250 \mathrm{~mL}$ Erlenmeyer flask, medium composition, whey supplemented with peptone : $1.5 \%$, glucose: $2.0 \%$ and ammonium chloride: $1.0 \%$.
\end{abstract}

Keywords: Lactic acid, whey, Lactobacillus delbruki

Short title: Lactic acid production from whey

\section{INTRODUCTION:}

Fermentative product Lactic acid is most widely used in food industries as preservative, acidulant and flavoring components. It is also used in pharmaceutical, cosmetic, textile and chemical industries for the production of lactate ester, propylene glycol, 2, 3-pentan dione, propionic acid, acrylic acid, acetaldehyde and dilactide [1]. Currently lactic acid consumption rate is increasing for the production of biodegradable polylacted (PLA) polymer, which is known as sustainable bio-plastic material [2]. Lactic acid naturally available in two form: $\mathrm{d}(-)$-lactic acid and $1(+)$-lactic acid. Higher amount of $\mathrm{d}(-)$-lactic acid are harmful to humans [3]. $\mathrm{L}(-)$ isomer of lactic acid is preferably used for food related and pharmaceutical applications.

Commercially lactic acid is produced by means of chemical synthesis or by fermentation. Racemic mixture of two optical isomers of lactic acids are the result of chemical synthesis, where fermentation process can yield an optically pure form of lactic acid or racemate, depending on microorganisms, substrate and fermentation conditions for the production [4].

Generally lactic acid is produced by hydrolysis of acetonitril derivatives from acetaldehyde and hydrogen cyanide, which are produced by petrochemical process. So, chemical synthesis may be limited due to limiting source of naturally available raw materials in future and negative feature for environmental pollution. Whereas renewable sources including lingocellulose, starch, agricultural waste materials, sugars are abundant substrates for fermentative production.
Whey, the greenish translucent liquid obtained from milk after precipitation of casein, has been viewed as one of the major disposal problems of the dairy industry, because of the high volumes produced and having a high biochemical oxygen demand $[5,6]$. As a general rule, about nine litres of whey is obtained for every kilogram of cheese produced.

Thus, the volume of whey to be processed, originating from just one typical large scale cheese making operation can exceed 1 x $106 \mathrm{~L} /$ day. A dairy farm processing $100 \mathrm{t}$ of milk per day produces approximately the same amount of organic products in its effluent, as would a town with 55000 residents [7].

The production of these products in large quantities leads to enormous quantities of whey as a byproduct in the dairy industries, which represents $85-95 \%$ of the milk volume and retains $55 \%$ of milk nutrients. Among the most abundant of these nutrients are lactose, soluble proteins, lipids and mineral salts $[5,6]$. The availability of carbohydrate reservoir of lactose in whey and presence of other essential nutrients for the growth of microorganisms makes the whey one of the potential substrate for the production of different bio-products through biotechnological means [3]. Microbial fermentation has the advantage that by choosing a strain of lactic acid bacteria (LAB) producing only one of the isomers, an optically pure product can be obtained, whereas synthetic production always results in a racemic mixture of lactic acid. The production of optically pure lactic acid is essential for the polymer synthesis in which lactic acid is used $[8,9,10]$. Moreover, $\mathrm{L}(+)$ lactic acid is used by human metabolism due 
to the presence of L-lactate dehydrogenase and is preferred in foods as preservative as well as emulsifier $[8,11]$.

Presently, starch or sugar containing substances are used for the production of lactic acid. Whey is the attractive raw material for lactic acid production for its low cost, low levels of contaminants, fast fermentation rate, high lactic acid yield, little or no by-product formation, ability to be fermented with little or no pretreatment, year-round availability and reduction of waste products.

The present paper deals with the production of lactic acid using whey supplemented with different components.

\section{MATERIALS\& METHODS}

\subsection{Preparation of whey:}

Calcium lactate was added at boiling condition to cuddle down protein portion from milk. Coagulated protein was separated from whey by filtration technique.

\subsection{Microorganism:}

Lyophilized culture of Lactobacillus delbrukii MTCC 911, was procured from supplied by MTCC, Chandigarh.

\subsection{Maintenance and cultivation of the culture:}

The bacterial culture was revived on MRS (de Mann Rogosa Sharpe) broth with $\mathrm{pH} 6.2 \pm 0.2$. The process of activation of the freeze dried culture was carried out on a regular basis by transferring them after every $48 \mathrm{~h}$ up to three generations. The culture was maintained on MRS (MRS medium supplemented with $30.0 \mathrm{gm} / \mathrm{L}$ agar) by subculturing, aseptically at fortnight intervals and stored at $4^{\circ} \mathrm{C}$, until further use [12].

\subsection{Preparation of starter culture:}

The bacterial culture was grown in $50 \mathrm{~mL}$ of MRS medium in $250 \mathrm{~mL}$ Erlenmeyer flask. After sterilization, the medium was inoculated with a loopful of cells from agar stab and incubated at $37^{\circ} \mathrm{C}$ for $24 \mathrm{~h}$ under stationary conditions[12].

\subsection{Fermentation medium:}

Whey was supplemented with yeast extract $(0.75 \%$, w/v), manganese sulphate $(20 \mathrm{mg} / \mathrm{L})$, andcalcium carbonate $(1.5 \%$, w/v) [12]. The whey medium was sterilized at $121^{\circ} \mathrm{C}$ for 15 min. Thefermentation medium prepared in this way was used for the production of lactic acid usingLactobacillus delbrukiicells.

\subsection{Optimization of process parameters:}

Different process parameters such as $\mathrm{pH}$, inoculum size, temperature, composition of fermentation medium and incubation period were optimized by varying the respective parameters to enhance lactic acid production from whey medium.

\subsection{Assay method:}

After completion of fermentation the fermented broth was centrifuged at $10,000 \mathrm{rpm}$ for $10 \mathrm{~min}$ to pellet out the bacterial growth. Then the supernatant was used for estimation of lactic acid by titrimetric method [13].

\section{RESULTS \& DISCUSSION}

\subsection{Optimization of medium volume:}

The effect of medium volume on lactic acid production was performed by varying medium volume from $50 \mathrm{~mL}$ to $150 \mathrm{~mL}$ (Fig. 1). The maximum lactic acid production $(1.52 \mathrm{gm} / \mathrm{L})$ was observed at volume $125 \mathrm{~mL}$ in $250 \mathrm{~mL}$ Erlenmeyer flask at $\mathrm{pH}$ 6.8 and $420 \mathrm{C}$ on 24 h.Oxygen requirement of microorganisms during growth and fermentation is indicated by medium volume in a specified flask volume. Because air is penetrated by cotton and mixed in medium, mixing of air is dependant on available surface area, which is decreased with medium volume in a same size flask.

\subsection{Effect of pH}

The effect of $\mathrm{pH}$ on lactic acid production was evaluated by using fermentation medium having apH range of 5.5-7.0 (Fig. $2)$. The maximum lactic acid production $(1.53 \mathrm{gm} / \mathrm{L})$ was observed at $\mathrm{pH} 6.8$ on $24 \mathrm{~h}$.

However, at higher and lower $\mathrm{pH}$ levels, a decrease in the both the function was observed, with significant decrease at $\mathrm{pH} 6.0$ and 7.0. A pH range of 6.0-6.5 has been reported optimal for lactic acid production using L. caseistrain [14]. However, $\mathrm{pH}$ 5.5 has been used for lactic acid production using $\mathrm{L}$. helveticusby [15]. From the above observations, a pH 6.8 was considered optimal for maximum lactic acid production. In the subsequent experiments, the $\mathrm{pH}$ of the fermentation medium was adjusted to 6.8 .

\subsection{Effect of inoculum size}

To study the influence of inoculum size on the lactic acid production, different inoculum levels $(1-5 \%, \mathrm{v} / \mathrm{v})$ were added to the fermentation medium (Fig. 3). The lactic acid production increased with the increase in inoculum size up to $4 \%(\mathrm{v} / \mathrm{v})$, thereafter no improvement in both the functions was observed. The maximum lactic acid production of $2.52 \mathrm{gm} / \mathrm{L}$ was observed with $4 \%(\mathrm{v} / \mathrm{v})$ inoculum of bacterial culture. The low lactic acid production at $1 \%(\mathrm{v} / \mathrm{v})$ inoculum level could be attributed to the low density of starter culture. The use of $2 \%$ $(\mathrm{v} / \mathrm{v})$ inoculum for the lactic acid production has been reported in earlier studies also $[16,17]$. However, the higher inoculum $(3 \%, \mathrm{v} / \mathrm{v})$ has also been used for lactic acid production [18]. From the above observations, an inoculum of $4 \%(\mathrm{v} / \mathrm{v})$ could be considered optimal for achieving maximum lactic acid 
production using $24 \mathrm{~h}$ old inoculum, however, $4 \%(\mathrm{v} / \mathrm{v})$ inoculum size was used in the subsequent studies.

\subsection{Effect of temperature}

To find the optimum temperature for lactic acid production, whey medium after inoculation wasincubated at a temperature range of $40-50^{\circ} \mathrm{C}$. Lactic acid production increased with increase in the temperature up to $42^{\circ} \mathrm{C}$; however, an insignificant decrease was found at $45^{\circ} \mathrm{C}$ (Fig. 4). Other tested temperatures displayed low values of lactose utilization and lactic acid production. The maximum lactic acid production of $2.53 \mathrm{gm} / \mathrm{L}$ was observed at $42^{\circ} \mathrm{C}$. The temperature is also one of the important factors, which influences the activity of metabolic/cell enzymes. Enzymes are most active at optimum temperature and enzymatic reaction proceeds at maximum rate. However, below and above optimal temperature reaction rate is decreased which causes the problems in cell metabolism The optimal temperature for growth of lactic acid bacteria varies between the genera from 20 to $45^{\circ} \mathrm{C}$ [19]. In fermentations using $\mathrm{L}$. delbrueckii, and L.bulgaricusa temperature of $45^{\circ} \mathrm{C}$, or higher may be maintained (Buchta, 1983)[20]. L. helveticus, and L.acidophiluscan be used in a temperature range of $37-45^{\circ} \mathrm{C}$. Krischke et al. [14] have used $37^{\circ} \mathrm{C}$ temperature for lactic acid production using L.casei. However, a temperature of $28^{\circ} \mathrm{C}$ has also been reported optimal for L. caseiin a separate study [21]. From the above observations, a temperature of $42^{\circ} \mathrm{C}$ was considered optimal for lactose conversion to lactic acid using bacterial cells; however, a temperature of $42^{\circ} \mathrm{C}$ was selected for further experimentation.

\subsection{Effect of incubation period}

To find out the optimal incubation time for the maximal lactic acid production, the whey medium inoculated with bacterial culture was incubated for $48 \mathrm{~h}$ under the above optimized conditions. The samples were drawn at specified time intervals and the results obtained are presented in Fig. 5. As evident from the results, an increase in lactose utilization and subsequent lactic acid production was found up to $24 \mathrm{~h}$ and thereafter no improvement in both the functions was observed. This could be attributed to the growth of the culture reached to thestationary phase and as a consequence of metabolism, microorganisms continuously change the characteristics of the medium and the environment. A maximum lactic acid production of $2.58 \mathrm{gm} / \mathrm{L}$ was observed after $48 \mathrm{~h}$ of incubation. The reduction in fermentation period is additionally advantageous to improve the economics of the process. Therefore, an incubation time of $24 \mathrm{~h}$ was considered optimal for maximum lactose conversion to lactic acid. The incubation period of $48 \mathrm{~h}$ has been generally used for lactic acid production using different lactobacilli cultures [17, 18, 22]. From the observations made during the process optimization studies, it could be concluded that maximum lactose conversion to lactic acid was obtained with the process conditions of $\mathrm{pH} 6.8$, temperature $42^{\circ} \mathrm{C}$ and inoculum size $4 \%$ $(\mathrm{v} / \mathrm{v})$ with an incubation of $24 \mathrm{~h}$. The different optimal conditions reported by various workers for maximum lactic acid production could be explained by the differences in the nature of the strains and medium composition used in their studies. The above optimized process parameters can be used in scale up studies in further investigations.

\subsection{Optimization of supplement concentration}

Whey contains lesser amount of carbon and nitrogen sources. So the medium was enriched with different concentration of peptone, glucose and ammonium chloride. Concentrations were varied from $1.0-2.5 \%$ and other environmental conditions maintained constant. Productivity of lactic acid was increased with increase in peptone concentration from 1 to $1.5 \%$ and then remained about constant $(8.53 \mathrm{gm} / \mathrm{L})$. Similarly it was also increased with glucose concentration from 1 to $2.0 \%$, then decreased (maximum production was $8.54 \mathrm{gm} / \mathrm{L}$ ) and productivity was about constant with ammonium chloride concentration $(4.1 \mathrm{gm} / \mathrm{L})$. After optimization of all of these parameters productivity was $12.22 \mathrm{gm} / \mathrm{L}$ at $\mathrm{pH} 6.8$, inoculum volume $4 \%$, peptone concentration $1.5 \%$, glucose $2.0 \%$, ammonium chloride $1.0 \%$ and medium volume was taken as $125 \mathrm{~mL}$ in $250 \mathrm{ml}$ Earlenmeyer flask at $420 \mathrm{C}$.

\section{CONCLUSIONS}

Whey is the waste byproduct of milk industry, which can be used for lactic acid production. Lactic acid production was $12.22 \mathrm{gm} / \mathrm{L}$ at $\mathrm{pH}: 6.8$, temperature: $420 \mathrm{C}$, Inoculum volume: $4 \%$, fermentation time: $24 \mathrm{~h}$, medium volume: $125 \mathrm{~mL}$ in 250 $\mathrm{mL}$ Erlenmeyer flask, medium composition whey supplemented with peptone : $1.5 \%$, glucose: $2.0 \%$ and ammonium chloride: $1.0 \%$.

\section{ACKNOWLEDGEMENTS}

The authors like to express their gratitude to the management authority of Techno India, Salt lake, Kolkata for providing the necessary infrastructure facilities to carry out this work.

\section{REFERENCES}

[1]. Davison, B.B., Llanos, R.L., Cancilla, M.R., Redman, N.C. and Hillier, A.J. "Current research on the genetics of lactic acid production in lactic acid bacteria", Int. Dairy J.,5:763-784(1995).

[2]. Datta, R., Tsai, S.P., Bonsignor, P., Moon, S. and Frank, J., "Technological and economic potential of poly(lactic acid) and lactic acid derivatives", FEMS Microbiol. Rev., 16, pp. 221-231 (1995).

[3]. Hofvendahl, K. and Hagerdal, B. H., "Factors Affecting the Fermantative Lactic Acid Production from Renewable Resources". J. of Enzymes and Microbial Technol, 26, pp.87107 (2000).

[4]. Benninga, H., A History of Lactic Acid Making, Kluwer Academic Publishers, Dordrecht, Netherlands (1990). 
[5]. Marwaha, S.S. and Kennedy, J.F., "Review: whey pollution problem and potential utilization", Int.J. Food Sci. Technol., 23, pp. 323-336 (1988).

[6]. Mawson, A.J., "Bioconversions for whey utilization and waste abatement", Biores. Technol.,47, pp. 195-203 (1994).

[7]. Sienkiewicz, T. and Riedel, C.-L., Whey and Whey Utilization. Th Mann, Germany, (1990).

[8]. Litchfield, J.H., "Microbial production of lactic acid", Adv. Appl. Microbiol.,42, pp.45-95 (1996).

[9]. Lunt, J., "Large-scale production, properties and commercial applications of polylactic acid polymers", Polymer Degrad. Stability, 59, pp. 145-152 (1998).

[10]. Amass, W., Amass, A. and Tighe, B., "A review of biodegradable polymers: uses, current developments in the synthesis and characterization of biodegradable polymers, blends of biodegradable polymers and recent advances in biodegradation studies", Polymer Int, 47, pp. 89-114 (1998).

[11]. Jarvi's, L., "Lactic acid outlook up as poly lactide nears market", Chemical Market Reporter, 26, pp.14 (2001).

[12]. Panesar, P.S., Kennedy, J.F., Knill, C.J. and Kosseva, M., "Production of $\mathrm{L}(+)$ Lactic Acid

usingLactobacillus caseifrom Whey”Braz. Arch. Biol. Technol., 53, pp. 219-226 (2010).

[13]. Aggarwal, S., "Isolation and characterization of starch degrading lactic acid bacteria", Master degree dissertation, Thapar Institute of Engg\& Technology, India (2006).

[14]. Krischke, W., Schroder, M. and Trosch, W., "Continuous production of L-lactic acid from whey permeate by immobilized Lactobacillus caseisubspcasei", Appl. Microbiol. Biotechnol.,34, pp. 573-578 (1991).

[15]. Ghaly, A.E., Tango, M.S.A., Mahmood, N.S. and Avery, A.C., "Batch propagation of Lactobacillus helveticusfor production of lactic acid from lactose concentrated cheese whey with microaeration and nutrient supplementation" World J. Microbiol. Biotechnol.,20, pp. 6575 (2004).

[16]. Roy, D., Goulet, J. and LeDuy, A., "Batch fermentation of whey ultrafiltrate by Lactobacillus helveticusfor lactic acid production”, Appl. Microbiol. Biotechnol.,24, pp. 206-213 (1986).

[17]. Gandhi, D.N., Patel, R.S., Wadhwa, B.K., Bansal, N., Kaur, M. and Kumar, G., "Effect of agro-based by-products on production of lactic acid in whey permeate medium", J. Food Sci.Technol., 37, pp. 292-295 (2000).

[18]. Chiarini, L., Mara, L. and Tabacchioni, S., "Influence of growth supplements on lactic acid

production in whey ultrafiltrate by Lactobacillus helveticus", Appl. Microbiol. Biotechnol.,36, pp. 461-464 (1992).

[19]. Wood B.J.B., Holzapfel W.H., The Genera of Lactic Acid Bacteria, Glasgow: Blackie Academic \& Professional, USA, (1995).

[20]. Buchta, K. Lactic Acid: In Biotechnology. Germany: VCH VerlagWeinheim(1983).

[21]. Nabi, B., Gh. R. and Baniardalan, P., "Batch and continuous production of lactic acid from whey by immobilized lactobacillus", J. Environ. Studies,30, pp. 47-53 (2004).

[22]. Kumar, S., Jha, Y.K. and Chauhan, G.S., "Process optimization for lactic acid production from whey using Lactobacillus strains". J. Food Sci.Technol.,38, pp. 5961(2001).

\section{LIST OF FIGURES:}

Fig 1: Effect of medium volume on lactic acid production Fig 2: Effect of $\mathrm{pH}$ on lactic acid production

Fig 3: Effect of inoculum volume on lactic acid production

Fig 4: Effect of temperature on lactic acid production

Fig 5: Effect of fermentation on lactic acid production

Fig 6: Optimization of supplements concentration (Peptone, glucose and ammonium chloride) for lactic acid production from whey.

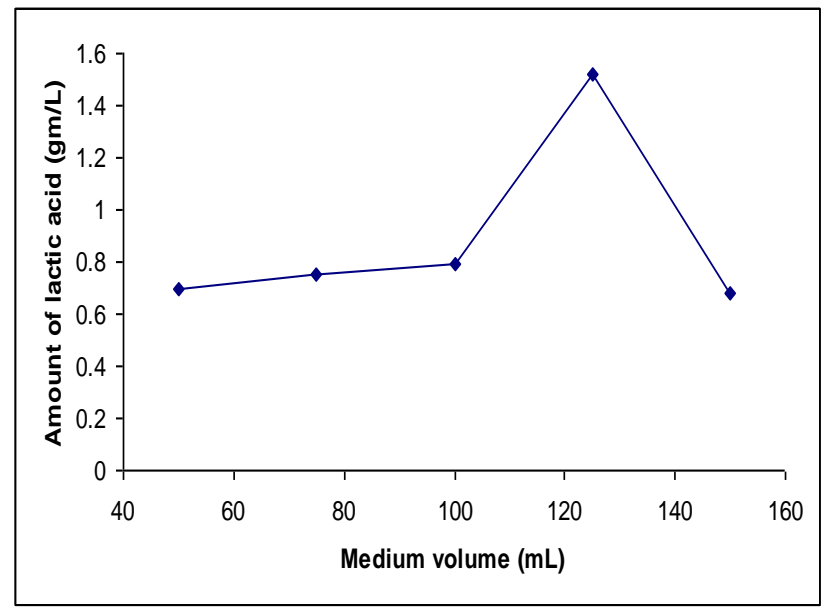

Fig 1: Effect of medium volume on lactic acid production

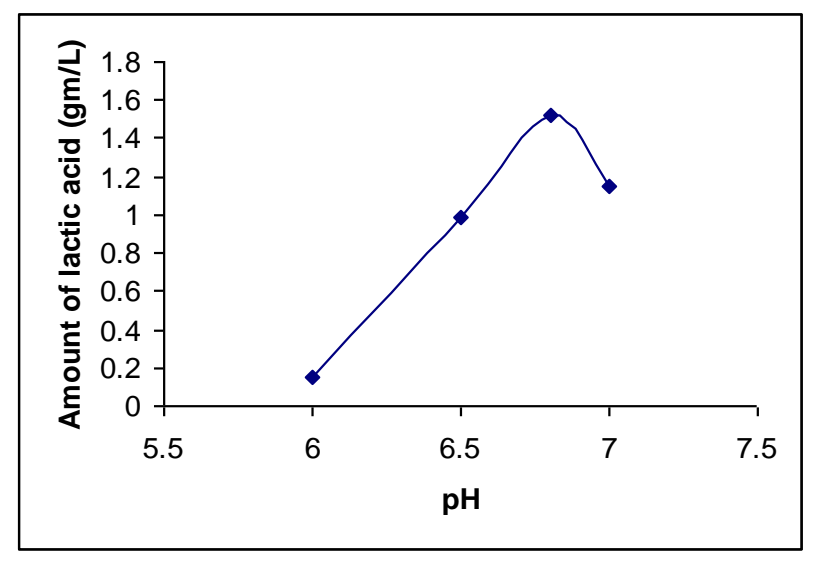

Fig 2: Effect of $\mathrm{pH}$ on lactic acid production 


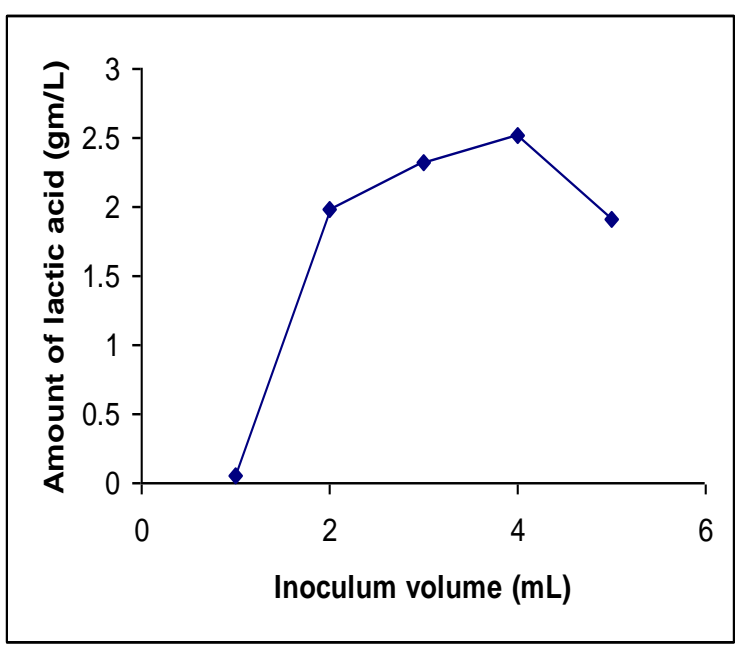

Fig 3: Effect of inoculum volume on lactic acid production.

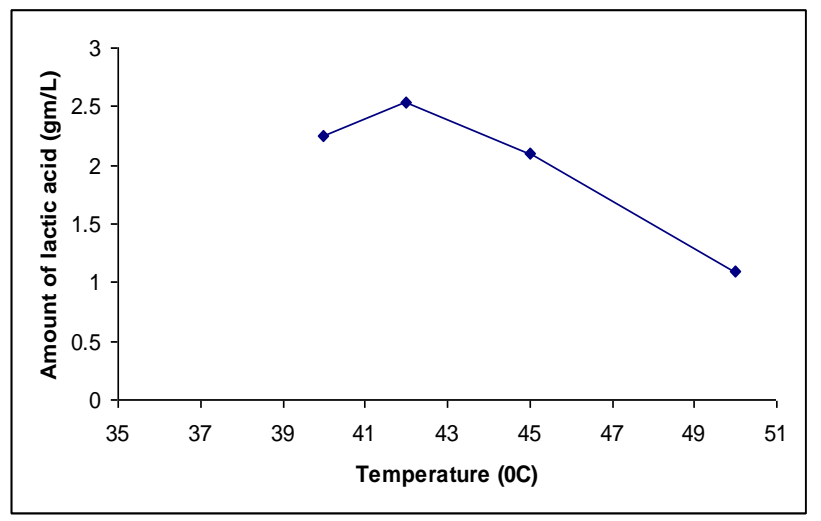

Fig 4: Effect of temperature on lactic acid production

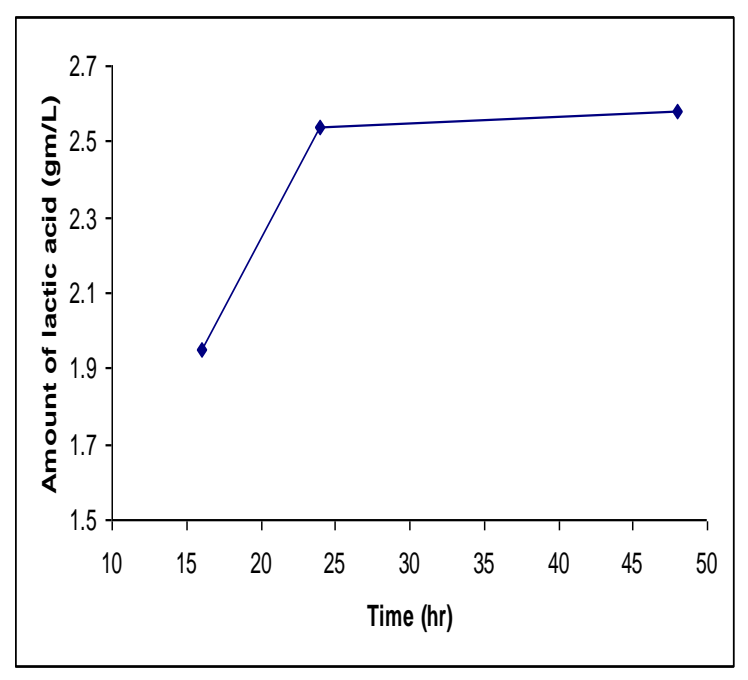

Fig 5: Effect of fermentation time on lactic acid production

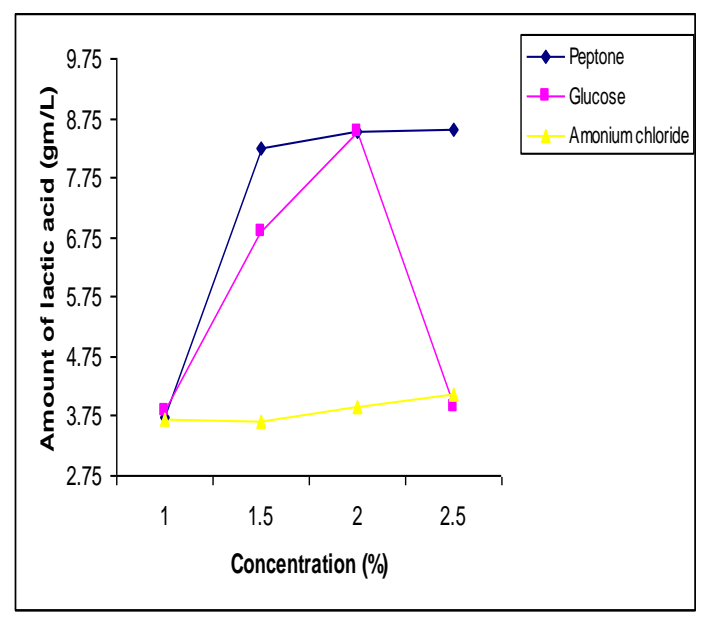

Fig 6: Optimization of supplement concentration (Peptone, glucose and ammonium chloride) for lactic acid production from whey. 